\title{
Effect of Sandblasting on Shear Bond Strength Composite Resin Veneer
}

\author{
Octarina $^{1}$, Andi Soufyan ${ }^{2}$, Yosi K. Eriwati² \\ ${ }^{1}$ Postgraduate program, Faculty of Dentistry, Universitas Indonesia, Jakarta 10430, Indonesia \\ ${ }^{2}$ Department of Dental Material, Faculty of Dentistry, Universitas Indonesia, Jakarta 10430, Indonesia \\ Correspondence e-mail to: octarina@yahoo.com
}

\begin{abstract}
Attachment between restoration and enamel surface in indirect resin composite veneer restoration (IRCV) is obtained using multi-step (MS) resin cement. Recently, a one step self-adhesive dual-cured resin cement (SADRC) was introduced. Objective: To determine the effect of sandblasting on shear bond strength (SBS) of IRCV to enamel using MS resin cement and SADRC. Methods: Forty specimens of buccal surface of enamel human premolar were used. The specimens were flattened and polished using silicon carbide. IRCV cylindrical specimens were light-cured in Solidilite chamber and were divided into two groups: IRCV without sandblasting $(n=20)$ and with sandblasting for 10 seconds $(n=20)$ and then bonded to enamel using MS $(n=10)$ and SADRC $(n=10)$, respectively. After 24h SBS of specimens were tested using a Universal Testing Machine. Data were analyzed statistically by one-way ANOVA. Results: The average SBS value of IRCV without SB and bonded with MS was $18.95 \pm 7.80 \mathrm{MPa}$ and MS with SB was $19.30 \pm 8.21 \mathrm{MPa}$. They were differ significantly with SADRC without SB $(4.85 \pm 2.12 \mathrm{MPa})$ and SADRC with $\mathrm{SB}(9.57 \pm 3.45 \mathrm{MPa})(p<0.05)$. Conclusion: Sandblasting significantly increased SBS VIRK to enamel using MS resin cement than SADRC.
\end{abstract}

\begin{abstract}
ABSTRAK
Efek sandblasting terhadap kekuatan rekat geser veneer indirek resin komposit. Perlekatan antara restorasi veneer indirek resin komposit (VIRK) dengan permukaan email diperoleh dari penggunaan resin semen multistep (MS). Material self-adhesive dual-cured resin cement (SADRC) dengan satu tahap pemakaian mulai banyak diperkenalkan. Tujuan: Untuk mengetahui efek sandblasting (SB) terhadap kekuatan rekat geser VIRK pada email dengan menggunakan resin semen multi-step dan SADRC. Metode: Empat puluh spesimen yaitu bagian bukal email gigi premolar manusia, diratakan dan dipoles menggunakan silikon karbida. Spesimen VIRK dimasukkan dalam ruang Solidilite untuk penyinaran, kemudian dibagi menjadi 2 grup, tanpa sandblasting $(\mathrm{n}=20)$ dan dengan sandblasting selama 10 detik $(\mathrm{n}=20)$. Selanjutnya direkatkan pada email dengan menggunakan resin semen multi-step $(\mathrm{n}=10)$ dan SADRC $(\mathrm{n}=10)$. Setelah 24 jam disimpan dalam inkubator, kekuatan rekat geser spesimen diuji menggunakan Universal Mechanical Testing Machine. Data dianalisis statistik dengan uji oneway ANOVA. Hasil: Nilai rata-rata kekuatan rekat geser multi-step tanpa SB $(18,95 \pm 7,80 \mathrm{MPa})$ dan multi-step SB $(19,30 \pm 8,21 \mathrm{MPa})$ memiliki perbedaan bermakna dengan SADRC tanpa SB $(4,85 \pm 2,12 \mathrm{MPa})$ dan SADRC dengan SB $(9,57 \pm 3,45 \mathrm{MPa})(p<0,05)$. Simpulan: Sandblasting dapat meningkatkan kekuatan rekat geser VIRK pada email yang menggunakan resin semen multi-step dibandingkan dengan SADRC.
\end{abstract}

Key words: indirect composite resin veneer, resin cement multi-step, SADRC, sandblasting

\section{PENDAHULUAN}

Estetika pada bidang kedokteran gigi merupakan hal yang penting, terutama untuk restorasi gigi anterior. Salah satu restorasi estetik yang banyak diminati adalah restorasi veneer untuk gigi anterior. Restorasi veneer digunakan untuk melapisi bagian labial gigi vital yang mengalami kerusakan maupun gigi nonvital yang mengalami perubahan warna, fraktur gigi sebagian, gigi displasia atau hipoplasia. ${ }^{1,2}$

Restorasi veneer indirek umumnya dapat dibuat dari material keramik atau material resin komposit yang dkerjakan di luar mulut pasien atau di laboratorium. 
Restorasi veneer indirek dengan menggunakan resin komposit memiliki beberapa keuntungan, antara lain dapat menghasilkan bentuk anatomi dan morfologi serta estetik yang baik, menghasilkan adaptasi tepi yang baik, serta memiliki kekuatan yang cukup untuk menahan beban kunyah. Apabila terjadi fraktur, potensi perbaikan pada restorasi veneer indirek resin komposit lebih mudah dibandingkan dengan keramik, karena dapat dilakukan langsung di dalam mulut pasien. ${ }^{3-5}$

Restorasi veneer indirek resin komposit (VIRK) memiliki komposisi yang sama dengan resin komposit yang digunakan sebagai tumpatan langsung sewarna gigi, yaitu terdiri dari campuran matriks resin organik, filler anorganik, dan coupling agent. Material ini dibuat dengan kombinasi proses panas, tekanan vakum, dan intensitas sinar yang tinggi, sehingga menghasilkan sifat fisik dan mekanik yang lebih baik dibandingkan dengan resin komposit untuk restorasi direk. ${ }^{2,4}$ Sebelum veneer indirek resin komposit direkatkan pada email, bagian permukaan yang akan direkatkan dapat dilakukan sandblasting. Tujuan sandblasting (SB) ini adalah untuk meningkatkan energi permukaan VIRK dengan terjadinya degradasi non selektif pada matrik resin dan terbukanya partikel filler anorganik yang akan menyediakan ruangan untuk adhesi dengan resin semen. ${ }^{4}$ Sandblasting dapat dilakukan di laboratorium dental maupun dalam ruang praktek menggunakan partikel aluminium oksida berukuran $30-50 \mu \mathrm{m}$.

Penelitian sebelumnya menggunakan SB pada restorasi VIRK selama 10 detik dengan jarak $5 \mathrm{~mm}$ serta tekanan 2bar menunjukkan hasil rata-rata kekuatan rekat sebesar 16,51MPa. Hasil kekuatan rekat ini lebih besar dibandingkan dengan kekuatan rekat restorasi veneer yang tidak diberi perlakuan SB. ${ }^{6}$ Hal senada dengan penelitian lain yang menyatakan bahwa SB selama 10 detik pada permukaan restorasi VIRK dengan partikel aluminium oksida $50 \mu \mathrm{m}$ menghasilkan kekuatan rekat sebesar 23,28 sampai 53,05MPa.

Suatu restorasi VIRK memerlukan perlekatan yang kekuatan dengan permukaan gigi agar restorasi tersebut tidak mudah lepas. Perlekatan ini umumnya menggunakan bahan adhesif. Resin semen merupakan bahan adhesif yang paling banyak digunakan untuk melekatkan inlay, onlay, veneer, dan crown yang terbuat dari material keramik, logam maupun resin komposit. ${ }^{8,9}$ Berbagai macam resin semen yang digunakan antara lain resin semen dengan prosedur aplikasi multi-step, yaitu melalui proses etsa dengan asam fosfat, setelah priming dan bonding. Dengan berkembangnya teknologi bahan adhesif, telah diperkenalkan Self-adhesive dual-cured resin cement (SADRC) yang merupakan produk baru resin semen dengan satu tahap aplikasi. SADRC disebutkan dapat berikatan dengan jaringan gigi tanpa adanya aplikasi etch, prime, dan bond, sehingga aplikasinya lebih mudah dan mengurangi tahapan klinis. SADRC disebutkan juga dapat berikatan secara kimia dengan mengadakan chelation terhadap struktur gigi. SADRC juga memiliki beragam warna untuk menghasilkan estetik yang baik. ${ }^{8,10}$ Namun efek SADRC terhadap kekuatan rekat geser restorasi veneer indirek saat ini belum banyak diketahui. Penelitian ini bertujuan untuk mengetahui efek sandblasting tehadap kekuatan rekat geser restorasi VIRK pada permukaan email menggunakan dua macam resin semen, yaitu multi-step (MS) dan SADRC.

\section{METODE}

Penelitian ini dimulai setelah mendapatkan persetujuan dari Komisi Etik Penelitian. Sampel penelitian adalah 40 gigi premolar manusia yang telah diekstraksi. Gigi yang telah diekstraksi direndam dalam larutan fisiologis. Spesimen email diambil dari bagian bukal gigi premolar kemudian diratakan menggunakan kertas silikon karbida no. 2000, sebanyak 0,3-0,5mm, dengan menggunakan alat Struers LaboPol-21 (Germany). Selanjutnya gigi dipotong $2 \mathrm{~mm}$ di bawah cementoenamel junction menggunakan carborundum disc, kemudian bagian mahkota ditanam dalam resin dekoratif pada PVC dengan diameter $2 \mathrm{~cm}$ dan tinggi $1 \mathrm{~cm}$.

Spesimen VIRK dibuat dengan cetakan silinder berdiameter $3 \mathrm{~mm}$ dan tinggi $3 \mathrm{~mm}$, kemudian dipolimerisasi dengan sinar dalam alat Solidilite (Shofu, Japan) selama 3 menit dengan 4 lampu halogen dengan masing-masing intensitas sinar $800 \mathrm{~mW} / \mathrm{cm} 2$ (Tabel 1). Kemudian spesimen dibagi menjadi 2 grup: Grup 1. Spesimen VIRK tanpa sandblasting $(\mathrm{n}=20)$, yang kemudian dibagi menjadi 2 sub grup: Subgrup 1A: Aplikasi resin semen multi-step untuk perekatan pada permukaan email sesuai petunjuk pabrik. Subgrup 1B: Aplikasi SADRC untuk perekatan pada permukaan email sesuai petunjuk pabrik. Grup 2, Spesimen VIRK diberikan perlakuan SB $50 \mu \mathrm{m}$ selama 10 detik menggunakan alat ECO SB (Italy), kemudian dibagi menjadi 2 subgrup: Subgrup 2A: Aplikasi resin semen MS untuk perekatan pada permukaan email sesuai petunjuk pabrik. Subgrup 2B: Aplikasi SADRC untuk perekatan pada permukaan email sesuai petunjuk pabrik.

Setelah direkatkan, seluruh spesimen direndam dalam larutan fisiologis pada suhu $37^{\circ} \mathrm{C}$ selama 24 jam. Semua spesimen kemudian diuji kekuatan rekat geser (shear bond strength) menggunakan Universal Mechanical Testing Machine dengan crosshead speed $0,5 \mathrm{~mm} / \mathrm{min}$ dengan beban $50 \mathrm{kgf}$ hingga spesimen lepas.

Data yang diperoleh dianalisis dengan menggunakan One Way ANOVA dan post hoc Tukey HSD (SPSS for Windows versi 17.0), untuk melihat perbedaaan kekuatan rekat geser (shear bond strength) dari keempat grup $(p<0,05)$. 
Tabel 1. Material yang digunakan beserta komposisi dan prosedur aplikasi

\begin{tabular}{|c|c|c|c|c|}
\hline Material & Merk & Manufaktur & Komposisi & Prosedur Aplikasi \\
\hline VIRK & Ceramage Body & Shofu, Kyoto, Japan & $\begin{array}{l}\text { Zirconium silate filler } \\
\text { (amorphous), UDMA dan } \\
\text { lainnnya }\end{array}$ & $\begin{array}{l}\text { Spesimen dibuat dengan mold } \\
\text { silindris berukuran } 3 \times 3 \mathrm{~mm} \\
\text { dan dimasukkan dalam alat } \\
\text { curing Solidilite selama } 3 \\
\text { menit }\end{array}$ \\
\hline $\begin{array}{l}\text { Aluminium } \\
\text { Oxide }\end{array}$ & $\begin{array}{l}\text { Bubuk } \\
\text { Sandblasting }\end{array}$ & $\begin{array}{l}\text { Eisenbacher, } \\
\text { Germany }\end{array}$ & Aluminium oksida $50 \mu \mathrm{m}$ & $\begin{array}{l}\text { Bubuk aluminium oksida } \\
\text { dimasukan ke dalam alat } E C O \\
\text { sandblasting, dan semprotkan } \\
\text { pada permukaan restorasi } \\
\text { dengan tekanan } 2 \text { bar, jarak } \\
10 \mathrm{~mm} \text {, diameter nozzle } 1 \mathrm{~mm} \\
\text { selama } 10 \text { detik. }\end{array}$ \\
\hline \multirow[t]{4}{*}{$\begin{array}{l}\text { Resin Semen } \\
\text { MS }\end{array}$} & Total Etch & $\begin{array}{l}\text { Ivoclar Vivadent, } \\
\text { Schaan } \\
\text { Liechtenstein }\end{array}$ & $37 \%$ phosphoric acid & $\begin{array}{l}\text { Aplikasikan total etch pada } \\
\text { permukaan email selama } \\
15 \text { detik, cuci dengan air } \\
\text { mengalir selama } 5 \text { detik dan } \\
\text { keringkan. }\end{array}$ \\
\hline & Excite F DSC & $\begin{array}{l}\text { Ivoclar Vivadent, } \\
\text { Schaan } \\
\text { Liechtenstein }\end{array}$ & $\begin{array}{l}\text { HEMA, dimethacrylate, phosp- } \\
\text { horic acid acrylate, highly } \\
\text { dispersed silicone dioxide, ini- } \\
\text { tiator, stabilizer dan potassium } \\
\text { fluoride dalam larutan alkohol }\end{array}$ & $\begin{array}{l}\text { Aplikasi Excite F DSC pada } \\
\text { permukaan email, gerakkan } \\
\text { kuas secara beraturan selama } \\
10 \text { detik kemudian semprot } \\
\text { dengan udara secara perlahan. }\end{array}$ \\
\hline & Monobond-S & $\begin{array}{l}\text { Ivoclar Vivadent, } \\
\text { Schaan } \\
\text { Liechtenstein }\end{array}$ & $\begin{array}{l}\text { Larutan alkohol dalam silane } \\
\text { methacrylate }\end{array}$ & $\begin{array}{l}\text { Aplikasi Monobond-S pada } \\
\text { permukaaan restorasi indirek } \\
\text { resin komposit selama } 60 \\
\text { detik kemudian semprot } \\
\text { dengan udara secara kekuatan. }\end{array}$ \\
\hline & Variolink N Base & $\begin{array}{l}\text { Ivoclar Vivadent, } \\
\text { Schaan } \\
\text { Liechtenstein }\end{array}$ & $\begin{array}{l}\text { Monomer: Bis-GMA, urethane } \\
\text { dimethacrylate dan triethylene } \\
\text { glycol dimethacrylate. } \\
\text { Filler inorganic: barium } \\
\text { glass, ytterbium triflouride, } \\
\text { Ba-Al-fluorosillicate glass dan } \\
\text { spheroid mixed oxide. } \\
\text { Bahan tambahan: initiator, } \\
\text { stabilizer dan pigmen. }\end{array}$ & $\begin{array}{l}\text { Aplikasi Variolink } N \text { Base } \\
\text { pada permukaan preparasi dan } \\
\text { restorasi, tekan selama } 3-4 \\
\text { detik. Light curing selama } 40 \\
\text { detik dengan intensitas sinar } \\
500 \mathrm{~mW} / \mathrm{cm}^{2} \text {. }\end{array}$ \\
\hline SADRC & Breeze & Pentron, USA & $\begin{array}{l}\text { BisGMA, UDMA, TEGDMA, } \\
\text { HEMA, 4-MET, Silane } \\
\text { treated barium glass, silica } \\
\text { (amorphous), minor additive, } \\
\text { Ca-Al-F silicate, curing } \\
\text { system }\end{array}$ & $\begin{array}{l}\text { Aduk kedua pasta dalam } \\
\text { mixing tip, aplikasi pada } \\
\text { permukaan, light curing } 40 \\
\text { detik. }\end{array}$ \\
\hline
\end{tabular}

\section{HASIL}

Hasil pengujian kekuatan rekat geser resin semen MS dan SADRC dapat dilihat pada Tabel 2. Nilai rerata kekuatan rekat geser VIRK menggunakan resin semen MS, tanpa SB $(18,95 \pm 7,80 \mathrm{MPa})$ dan dengan $(19,30 \pm 8,21 \mathrm{MPa})$ secara umum memiliki nilai kekuatan geser yang lebih besar dibandingkan VIRK dengan SADRC tanpa SB $(4,85 \pm 2,12 \mathrm{MPa})$ maupun dengan SB $(9,57 \pm 3,45 \mathrm{MPa})$. VIRK tanpa SB dengan resin semen multi-step memiliki nilai rerata kekuatan rekat geser yang lebih tinggi dan perbedaan ini secara statistik berbeda bermakna dibandingkan VIRK dengan 
SADRC tanpa SB. Demikian pula pada hasil kekuatan rekat geser VIRK dengan SB yang menggunakan MS, nilai rerata kekuatan rekat geser lebih tinggi dan secara statistik berbeda bermakna dibandingkan VIRK SADRC dengan SB. Analisis One-Way ANOVA diikuti dengan Post Hoc Tukey HSD menunjukkan pula bahwa kekuatan rekat geser VIRK dengan resin semen MS dengan SB tidak berbeda bermakna dengan yang tanpa SB.

\section{PEMBAHASAN}

Hasil penelitian ini menunjukkan perlakuan SB mempengaruhi kekekuatan rekat geser VIRK. Pengaruh perlakuan SB terhadap kekuatan rekat geser terlihat sangat bermakna terutama pada kelompok yang mengunakan one step SADRC. SB dilakukan dengan cara menyemprotkan 30-50 $\mu \mathrm{m}$ aluminium oksida pada permukaan restorasi dan akan menghasilkan ketidakteraturan pada permukaan VIRK. Ketidak teraturan berupa undercut dan groove akan memfasilitasi ikatan mikromekanik resin semen pada restorasi. ${ }^{6}$ Perlakuan SB pada VIRK juga akan menghilangkan kontaminasi pada permukaan, sehingga energi permukaan meningkat. ${ }^{7,11}$ Energi permukaan yang tinggi menyebabkan bahan adhesif resin semen mudah menyebar dan terserap pada permukaan restorasi VIRK sehingga menghasilkan adhesi yang baik dengan resin semen. ${ }^{12}$

VIRK dengan resin semen MS tanpa SB memiliki kekuatan rekat geser lebih rendah dibandingkan dengan grup dengan perlakuan SB. Namun demikian perbedaan kekuatan rekat geser keduanya ini tidak berbeda bermakna. Pada kondisi ini terlihat bahwa perlakuan SB tampaknya juga mempengaruhi kekekuatan rekat geser dibandingkan dengan yang tanpa SB. Nilai kekuatan rekat geser yang tinggi dari kedua grup ini juga dipengaruhi pula oleh praperlakuan VIRK yang menggunakan silane. Silane bertindak sebagai coupling agent yang dioleskan pada permukaan VIRK dengan SB maupun tanpa SB. Silane adalah molekul bifungsional yang berperan

Tabel 2. Nilai rerata dan standart deviasi kekuatan rekat geser veneer indirek resin komposit dengan resin semen multi-step dan SADRC

\begin{tabular}{lcc}
\hline $\begin{array}{c}\text { Grup perlakuan } \\
\text { VIRK }\end{array}$ & \multicolumn{2}{c}{$\begin{array}{c}\text { Rerata kekuatan rekat geser } \pm \text { SD } \\
\text { (MPa) }\end{array}$} \\
\cline { 2 - 3 } & $\begin{array}{c}\text { Resin semen } \\
\text { MS }\end{array}$ & SADRC \\
\hline $\begin{array}{l}\text { Grup 1. Tanpa } \\
\text { SB (n=20) }\end{array}$ & $18,95 \pm 7,80$ & $4,85 \pm 2,12$ \\
Grup 2.Dengan & $19,30 \pm 8,21$ & $9,57 \pm 3,45$ \\
SB (n=20) & & \\
\hline
\end{tabular}

sebagai bahan pengikat antara partikel anorganik pada VIRK dan bahan adhesif resin semen. Silane memiliki stuktur kimia R'-Si(OR), dimana R' adalah grup organo-fungsional. Grup organo-fungsional ini akan bereaksi dengan bahan adhesif resin semen golongan metakrilat, dan menciptakan ikatan ganda setelah polimerisasi. Grup alkil (OR) pada tahap hidrolisis akan menjadi sianolol ( $\mathrm{SiOH})$, dan akan membentuk ikatan kovalen dengan partikel anorganik silikon (Si-O-Si) guna melengkapi proses ikatan. ${ }^{4}$ Hasil ini sesuai dengan penelitian sebelumnya yang menyatakan bahwa silane justru meningkatkan kekuatan rekat geser sementara peran SB pada VIRK kurang memberikan nilai kekuatan rekat geser yang bermakna. ${ }^{13}$

Dalam penelitian ini, penggunaan resin semen MS atau SADRC pada permukaan email sangat berperan pada hasil uji kekuatan rekat geser. Pada grup resin semen MS, selalu dilakukan prosedur etsa, prime, dan bonding pada email. Perlakuan etsa dengan asam fosfat pada email akan membuka pori-pori dan menghilangkan smear layer, akibatnya permukaan email menjadi bersih dan energi permukaannya meningkat. Energi permukaan yang meningkat menyebabkan bahan adhesif mudah membasahi, melekat dan berpenetrasi ke dalam pori-pori email untuk membentuk resin tag pada waktu polimerisasi. Terbentuknya resin tag menyebabkan terjadinya ikatan mikromekanik yang kuat. ${ }^{14}$ Hal ini sesuai dengan penelitian sebelumnya yang menyatakan bahwa mekanisme terjadinya adhesi yang baik secara berurutan akan meliputi proses demineralisasi, pembasahan yang baik, difusi, penetrasi, dan polimerisasi resin semen. ${ }^{15}$

SADRC memiliki adhesi pada jaringan gigi tanpa melalui prosedur etsa atau aplikasi bahan bonding. Aplikasi yang lebih singkat dan dilakukan dalam satu tahapan menyebabkan bahan ini banyak digunakan di klinik. SADRC mengandung asam fosfat metakrilat dengan tingkat keasaman yang ringan. Setelah pengadukan kedua pasta, kandungan asam dengan $\mathrm{pH}$ yang lemah ini hanya akan mendemineralisasi email secara superfisial. Mekanisme ikatan SADRC ini lebih kepada ikatan kimia dibandingkan ikatan mekanik. Kelompok asam pada resin semen SADRC akan mengadakan chelation dengan ion kalsium hidroksiapatit dari email, dan menyebabkan terjadinya ikatan kimia. Asam lemah yang terkandung pada SADRC hanya melarutkan sebagian smear layer sehingga smear layer yang tertinggal ini akan menghalangi resin semen berpenetrasi ke permukaan email. Hal ini yang mempengaruhi kekuatan rekat gesernya menjadi lebih rendah. ${ }^{14}$ Sesuai dengan penelitian sebelumnya yang menggunakan resin semen one step tanpa perlakuan etsa dan bonding pada permukaan email, ternyata juga menghasilkan kekuatan rekat geser yang paling rendah $(7 \mathrm{MPa})$ dan dengan hasil patahan terdapat pada antar muka bahan adhesif dan permukaan email. ${ }^{16}$ Sebaliknya perlakuan 
pada permukaan email dengan etsa dan bonding memberikan nilai kekuatan rekat geser yang lebih besar (14MPa). ${ }^{16}$ Demikian pula dengan penelitian lain yang memperlihatkan bahwa penggunaan resin semen MS menghasilkan kekuatan rekat geser sebesar 35,2MPa, sedangkan dengan SADRC menghasilkan kekuatan geser yang lebih rendah yaitu $19,6 \mathrm{MPa} .{ }^{17}$ Penelitian lain memperlihatkan bahwa penggunaan asam fosfat $35 \%$ pada permukaan email sebelum perlekatan dengan SADRC ternyata dapat meningkatkan kekuatan rekat gesernya. ${ }^{18}$

\section{SIMPULAN}

SB pada permukaan restorasi VIRK dapat meningkatkan retensi resin semen MS dan SADRC. Penggunaan resin semen dengan kekuatan rekat geser sistem aplikasi MS memberikan kekuatan rekat geser yang lebih besar dibandingkan dengan sistem aplikasi SADRC.

\section{UCAPAN TERIMA KASIH}

Penulis mengucapkan terima kasih kepada pihak Laboratorium IMKG FKG UI, Kiang Multi Corp Grogol, dan Hans Dental Lab untuk informasi yang berguna, serta bantuan alat dan bahan yang digunakan dalam penelitian ini.

\section{DAFTAR PUSTAKA}

1. Dietschi D, Devigus A. Clinical approach to anterior adhesive restorations using resin composite veneer. Eur J Esthet Dent. 2011;6:17887.

2. Mangani F, Cerutti A, Putignano A, Bollero R, Madini L. Prefabricated composite veneers: Historical perspective, indications and clinical application. Eur J Esthet Dent. 2007;2:188-209.

3. Barone A, Derchi G, Rossi A, Marconcini S. Longitudinal clinical evaluation of Bonded composite inlay: A 3 year study. J Quintessence Int. 2008;39:65-71.

4. Soares CJ, Soares PV, Pereira JC, Fonseca RB. Surface treatment protocols in the cementation process of ceramic and laboratory-processed composite restoration: A literature review. J Esthet Restor Dent. 2005;17:224-35.

5. Passos SP, Ozan M, Vanderlei AD, Leite FPP, Kimpara ET, Bottino MA. Bond strength durability of direct and indirect composite system following surface conditioning to repair. J Adhes Dent.
2007;9:443-47.

6. D'Arcangelo C, Vanini L. Effect of three surface treatments on the adhesive properties of indirect resin composite restoration. J Adhes Dent. 2007;9:319-26.

7. Soares CJ, Giannini M, Oliveria MT, Martins LRM, Paulillo LAMS, Effect of surface treatment of laboratory fabricated composites on microtensile bond strength to a luting resin cement. J Appl Oral Sci. 2004;12:45-50.

8. Capa N, Ozkurt Z, Canpolat C, Kazazoglu E. Shear bond strength of luting agent to fixed prosthodontic restorative core materials. Aus Dent J. 2009;54:334-40.

9. Papazouglou E, Rahiotis C, Kakaboura A, Loukidis M. Curing efficacy of a photo and dual cured resin cement polymerized through 2 ceramics and resin composite. Int J Prosthodont. 2006;19:34-6.

10. Piwowarczky A, Lauer HC. Mechanical properties of luting cements after water storage. Oper Dent. 2003;28:535-42.

11. Sandblasting meaning and example sentences: meaning definition, sample sentence of sandblast. [Internet]. [Cited 2011 Aug 12]. Available from: http//www.dictionary30.com/meaning/ sandblasting.

12. Power JM, Sakaguchi RL. Restorative dental materials. 12th ed. St Louis: Mosby 2006:214-16.

13. Tbatabaei MH, Alizade Y, Taalim S. Effect of various surface treatment on repair strength of composite resin. J Dent TUMS. 2004;1:5-11.

14. Duarte Jr S, Sartori N, Sadan A, Phark JH. Adhesive resin cement to bonding esthetic restorations: A review. Quintenssence Dent Tech (QDT). 2011;34:40-66.

15. Van Landuyt KL, Snauwaert J, Munck JD, Pneumans M, Yoshida Y, Poitevin A, et al. Systematic review of the chemical composition of the contemporary dental adhesive. Biomater. 2007;28:3757-85.

16. Lin J, Shinya A, Gomi H, Shinya A. Bonding of self-adhesive resin cements to enamel using different surface treatment:bond strength and etching pattern evaluation. Dent Mater J. 2010;29: 425-32.

17. Hikita K, Van Meerbeek B, De Munck J, Ikeda $\mathrm{T}$, Van Landuyut K, Maida T, et al. Bonding effectiveness of adhesive luting agent to enamel and dentin. Dent Mater. 2007;23:829-39.

18. Duarte Jr S, Botta AC, Meire M, Sadan A. Microtensile bond strengths and scanning electron microscopic evaluation of self-adhesive and selfetch resin cements to intact and etched enamel. J Prosthet Dent. 2008;100:203-10. 